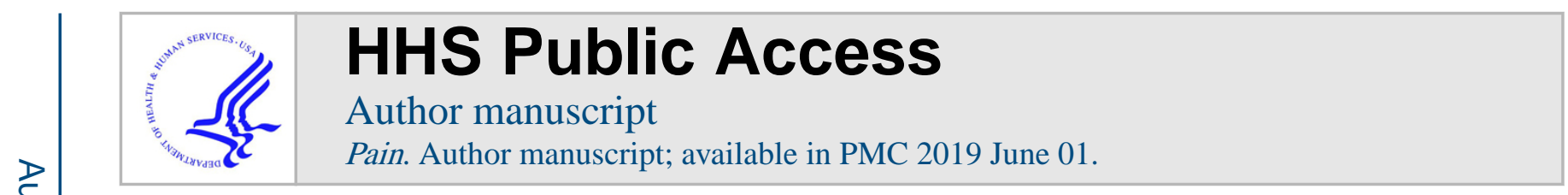

Published in final edited form as:

Pain. 2018 June ; 159(6): 1010-1011. doi:10.1097/j.pain.0000000000001223.

\title{
Pain after surgery
}

James C. Eisenach, MD and

FM James, III Professor of Anesthesiology, Wake Forest School of Medicine, Winston-Salem, NC, USA

Timothy J. Brennan, MD, PhD

Dr. Samir D. Gergis Professor of Anesthesia, University of lowa Carver College of Medicine, lowa City, IA, USA

Pain after major surgery likely contributes to 30 day major morbidity and mortality, treatment of postoperative pain contributes to sustained opioid use and misuse, and for some, surgery leads to persistent pain [6]. For these reasons a better understanding of acute and chronic pain after surgery is needed.

There are three main contributors to the severity and duration of postoperative pain. First, patients bring risk factors for more severe pain with them to surgery, the most important being pre-existing pain, chronic opioid use, and the surgical procedure to be performed [1]. Conversely, the peripartum period is associated with less severe and shorter lasting pain [7]. It's important to recognize, however, that predictive models have rarely been replicated from one study to another, and that risk factors common to many models together only are only fair predictors of the presence of long lasting pain.

Second, surgery obligatorily injures peripheral tissues, resulting in pain with a pathophysiology distinct from that of pure inflammation. As shown in preclinical rodent experiments, skin and muscle injury results in tissue hypoxemia and acidemia, release of inflammatory mediators, nerve growth factor (NGF), reactive oxygen species (ROS), lactate, and other factors which result in spontaneous activity, lowered threshold, and enlarged receptive fields of nociceptors, especially nociceptors of the A $\delta$ type $[2 ; 4 ; 8 ; 10 ; 11]$. Additional nerve injury adds a large reduction in receptive field area and increase in threshold in $A \beta$ afferents, a further increase in receptive field area in $A \delta$ afferents, and a further reduction in threshold for nociceptors [3].

Third, altered afferent input results in sensitization of the central nervous system processing and transmission of nociception, manifested as pain and areas of hypersensitivity to tactile stimuli. The mechanisms for this amplification and sensitization are manifold, but involve afferent release of glutamate (Glu), substance $\mathrm{P}(\mathrm{sP})$, calcitonin-gene related peptide (CGRP) and products from glia in the spinal cord [9]. Local anesthetics (LAs) administered alone or with opioids or a2-adrenoceptor agonists near the spinal cord inhibit pain transmission in this setting.

Correspondence: Dr. Eisenach, Department of Anesthesiology, Wake Forest School of Medicine, 1 Medical Center Boulevard, Winston-Salem, NC, 27157, USA. Phone: 336-716-4498. Fax: 336-716-2288. jimeisenach@ gmail.com. 
Local infiltration and perineural administration of local anesthetics and systemic nonsteroidal and steroidal anti-inflammatory drugs treat acute postoperative pain primarily by peripheral mechanisms whereas other systemic drugs such as opioids and ketamine or spinally administered drugs act primarily in the central nervous system. It's unclear whether anti-epileptic and anti-depressant drugs used to treat chronic pain reduce pain or opioid use after surgery, although the former are commonly used. Multi-modal pharmacologic, interventional, and non-pharmacologic methods as part of an enhanced recovery after surgery comprehensive program can shorten time to hospital discharge and reduce opioid use while in hospital. Despite all these treatment options, many patients continue to experience severe pain in the days following surgery [5], most likely reflecting both system failures and drug or treatment failures. And none of these treatments has been definitively demonstrated to either speed recovery from pain after hospital discharge, although multimodel treatment acutely after surgery can enhance analgesia, reduce side effects, and shorten time to hospital discharge.

\section{Acknowledgments}

Supported in part from grant P01 GM113852 from the National Institutes of Health, Bethesda, MD, USA to Dr. Eisenach. Dr. Eisenach has served as a consultant to Adynxx on development of treatments to speed recovery after surgery.

\section{References}

1. Andersen KG, Kehlet H. Persistent pain after breast cancer treatment: a critical review of risk factors and strategies for prevention. J Pain. 2011; 12(7):725-746. [PubMed: 21435953]

2. Banik RK, Brennan TJ. Sensitization of primary afferents to mechanical and heat stimuli after incision in a novel in vitro mouse glabrous skin-nerve preparation. Pain. 2008; 138(2):380-391. [PubMed: 18316159]

3. Boada MD, Gutierrez S, Aschenbrenner CA, Houle TT, Hayashida KI, Ririe DG, Eisenach JC. Nerve injury induces a new profile of tactile and mechanical nociceptor input from undamaged peripheral afferents. J Neurophysiol. 2015; 113(100):109.

4. Boada MD, Gutierrez S, Giffear K, Eisenach JC, Ririe DG. Skin incision-induced receptive field responses of mechanosensitive peripheral neurons are developmentally regulated in the rat. JNeurophysiol. 2012; 108(4):1122-1129. [PubMed: 22673323]

5. Breivik H, Stubhaug A. Management of acute postoperative pain: still a long way to go! Pain. 2008; 137(2):233-234. [PubMed: 18479824]

6. Chapman CR, Vierck CJ. The Transition of Acute Postoperative Pain to Chronic Pain: An Integrative Overview of Research on Mechanisms. J Pain. 2016; doi: 10.1016/j.jpain.2016.11.004

7. Eisenach JC, Pan P, Smiley RM, Lavand'homme P, Landau R, Houle TT. Resolution of Pain after Childbirth. Anesthesiology. 2013; 118(1):143-151. [PubMed: 23249931]

8. Kim TJ, Freml L, Park SS, Brennan TJ. Lactate concentrations in incisions indicate ischemic-like conditions may contribute to postoperative pain. JPain. 2007; 8(1):59-66. [PubMed: 16949881]

9. Pogatzki-Zahn EM, Segelcke D, Schug SA. Postoperative pain-from mechanisms to treatment. PAIN Reports. 2017; 2(2):e588. [PubMed: 29392204]

10. Sugiyama D, Kang S, Brennan TJ. Muscle Reactive Oxygen Species (ROS) Contribute to PostIncisional Guarding via the TRPA1 Receptor. PLoS One. 2017; 12(1):e0170410. [PubMed: 28103292]

11. Xu J, Brennan TJ. Guarding pain and spontaneous activity of nociceptors after skin versus skin plus deep tissue incision. Anesthesiology. 2010; 112(1):153-164. [PubMed: 19996955] 

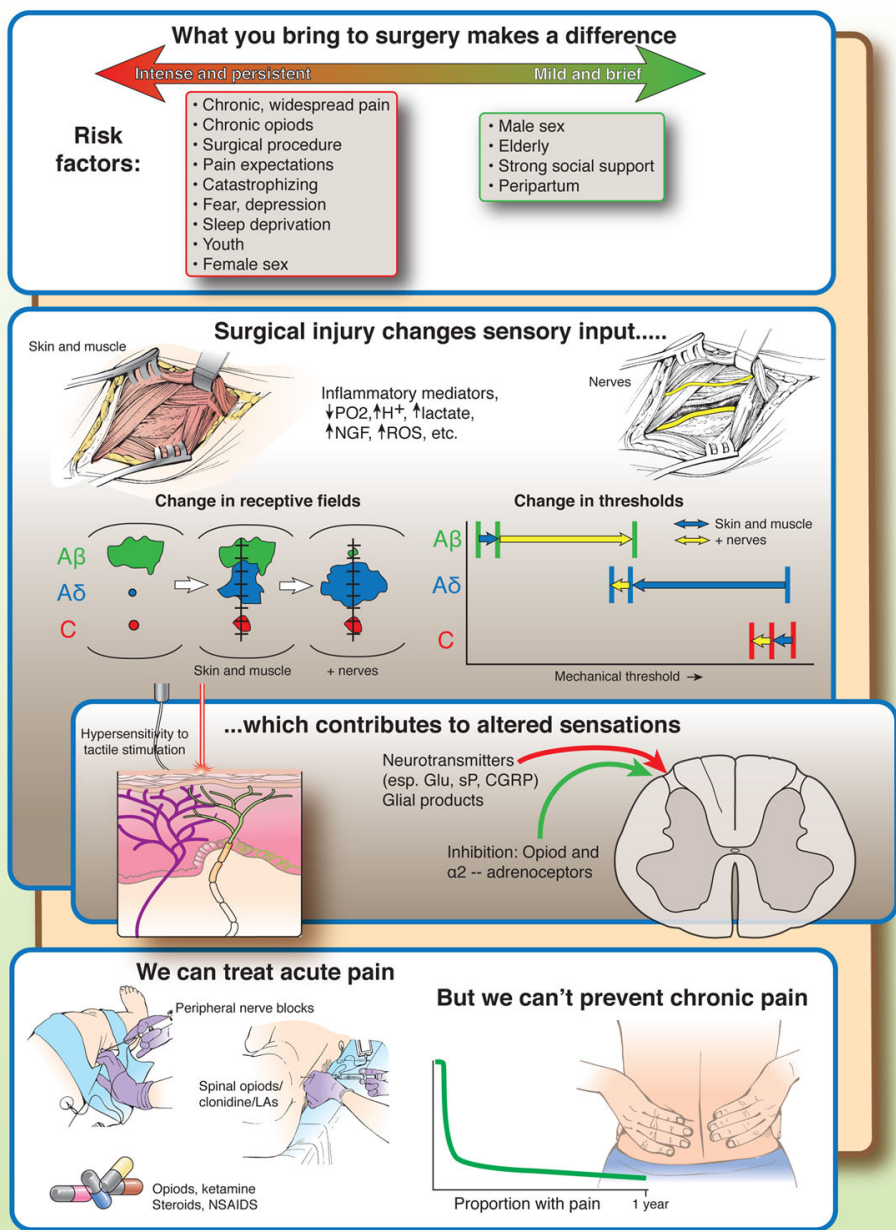

Figure. 